\title{
Osteopathic model of the development and prevention of occupational musculoskeletal disorders
}

https://doi.org/10.1515/jom-2020-0060

Received March 23, 2020; accepted September 16, 2020 ;

published online February 19, 2021

\begin{abstract}
Context: The direct and indirect costs of work-related musculoskeletal disorders are significant. Prevention is the most effective way to control these costs. To do that, we must understand how these disorders develop.

Objectives: To use the five models of osteopathic care to illustrate how cellular processes and neural reflexes interact to create work-related musculoskeletal pathology and to provide evidence-informed musculoskeletal injury and disability prevention recommendations.
\end{abstract}

Methods: A literature review of electronic databases (Google Scholar, PubMed, OVID, Cochrane Central Register of Controlled Trials, PEDro, and OSTMED.DR) from inception to October 16, 2019 and hand-search of publication references was performed for systematic reviews, cohort studies, case-control studies, and randomized controlled trials. The search terms reflected topics related to occupational injury and injury prevention, and included supplementary laboratory studies and narrative reviews related to the biological aspects of musculoskeletal injury. The eligible studies contained the following criteria: (1) the population of working age; (2) exposures to known risk factors, musculoskeletal disorders, and psychosocial factors; (3) written in English; (4) full text papers published in peer-reviewed journals; and (5) systematic review, cohort study, case-control study, and randomized controlled trial methodology. Studies were excluded if they included outcomes of productivity and costs only or outcomes that were assessed through qualitative methods only.

*Corresponding author: James William Price, DO, MPH, 14020 Old State Road, Evansville, IN 47725, USA; Ascension St. Vincent Occupational Medicine Clinic, Evansville, IN, USA; and College of Osteopathic Medicine, Marion University, Indianapolis, IN, USA, E-mail: james.price@ascension.org
Results: The literature search resulted in 1,074 citations; 26 clinical studies and 14 systematic reviews were used in this review. A comprehensive workplace musculoskeletal disorder prevention program should match demands to capacity, correct dysfunctional movement patterns, and limit tissue vulnerability (biomechanical-structural model); restore alpha-gamma balance, tonic-phasic synergistic function, and autonomic balance (neurological model); maximize physiologic reserve (metabolic-energy model) component of a prevention program; optimize respiration and circulation (respiratory-circulatory model); and address cognitive distortions (behavioral-biopsychosocial model).

Conclusions: The presented osteopathic model of the development and prevention of work-related musculoskeletal disorders suggests that a combination of preventive interventions will be more effective than any single preventive intervention.

Keywords: musculoskeletal disorders; occupational musculoskeletal disorders; work-related injury.

The direct and indirect costs of work-related musculoskeletal disorders are at least as great as the costs of cancer [1]. These costs are reflected in our economy, with a substantial portion being borne by employers, who must cover the expenses of medical care, lost productivity, absenteeism, hiring, and training [2]. However, the business sector does not cover all the expense of work-related musculoskeletal disorders; much of the cost is shifted to workers and their families, non-workers' compensation insurance carriers, and federal and state governments [3]. To prevent and manage work-related musculoskeletal injuries, we must first understand how the injuries develop.

Workers experience work-related musculoskeletal disorders categorized as overuse injuries and overexertion injuries [4]. Work-related overuse injuries, otherwise known as repetitive strain injuries, encompass a wide range of inflammatory and degenerative disorders [5]. Examples include carpal tunnel syndrome, shoulder impingement syndrome, lateral epicondylopathy, and 
tendinopathy of the wrist or hand [6]. These conditions are usually attributed to repetitive, forceful, or awkward movements $[4,7,8]$. Overexertion injuries occur when excessive stress is placed on muscles, ligaments, or tendons during resisted movement [7]. Mechanisms of overexertion include lifting, pushing, pulling, or carrying weights that exceed a person's capacity [7]. Workers also experience injuries related to slips, trips, falls, and blows. These injuries are typically related to environmental or performance issues and will not be discussed in this review.

This review presents a model for the pathogenesis of work-related musculoskeletal disorders. The proposed model considers the risk factors for occupational injuries and the biophysical processes for the development of pathology in the context of the five models of osteopathic care (i.e., behavioral-biopsychosocial model, biomechanical-structural model, metabolic-energy model, neurological model, respiratory-circulatory model) [9] (Figure 1). The intended purpose of the model is to provide a structure for making evidence-based recommendations for the prevention of work-related injury and disability. For this context, the objective of primary prevention is to limit the occurrence of work-related injury and disability. Secondary prevention programs are designed to prevent the progression of vague symptoms to overt pathology. The goal of tertiary prevention is to limit impairment and disability for workers with established musculoskeletal pathology.

\section{Methods}

Google Scholar, PubMed, OVID, Cochrane Central Register of Controlled Trials, PEDro, and OSTMED.DR were searched from inception of each database to October 16, 2019. A hand search of the reference lists of the articles meeting full-text eligibility was also performed. The following search terms were used: occupational injury, upper limb, neck and back injury prevention, ergonomics, stretching, exercise, posture, preplacement physical examinations, physical ability testing, job rotation, back schools, lifting education, cognitive behavioral training, and psychological interventions.

Eligible studies contained the following criteria: (1) the population of working age; (2) exposures to known risk factors (biomechanical overload, repetitive tasks, fatigue, posture at work, force, etc.), musculoskeletal disorders (pain, discomfort, injury, absence from work, absenteeism), and psychosocial factors (job satisfaction, stress, job control, engagement); (3) written in English; (4) full text papers published in peer-reviewed journals; and (5) systematic review, cohort study, case-control study, and randomized controlled trial (RCT) methodology. Studies were excluded if they included outcomes of productivity and costs only or outcomes that were assessed through qualitative methods only. Google Scholar was also searched for supplementary nonclinical studies and reviews related to the pathophysiology and behavioral science aspects of musculoskeletal injury.

The author (J.P.) screened all titles and abstracts identified by the searches after duplicate studies were removed. Full manuscripts of RCTs screened as potentially relevant were assessed for quality using the National Institute for Health and Care Excellence (NICE) methodology checklist for cohort studies [10]. The NICE checklist evaluates the risk of selection bias, performance bias, attrition bias, and detection bias. To increase objectivity, each type of bias was assigned a numerical value of $0-3(0=$ low risk, $1=$ lowmoderate risk, $2=$ moderate-high risk, $3=$ high risk) bases on the number of positively identified risk factors for each category. The mean score was used to generate an overall risk of bias score. Studies with an overall risk of bias score of 2 or greater were eliminated from the review. Any remaining studies deemed high risk for an individual category of bias were also excluded. A risk of bias table was used to present these findings (Table 1).

To bring clarity to a complex topic, the information gleaned from these articles was then categorized and organized into the five models of osteopathic care. Each model was split into pathophysiology and preventive intervention subdivisions. This material was analyzed in a level of evidence table (Table 2).

\section{Results}

Of the 1,074 citations identified through the literature search, 1,010 were excluded through title and abstract screening. Among the 64 full-text articles full-text articles assessed, 23 did not meet inclusion criteria, and 11 did not present their findings as numerical values with confidence intervals or standard deviations. The remaining 30 studies [11-40] were assessed using the NICE checklist, and four were determined to have unacceptable risk of bias. The remaining 26 studies were used in this review (Figure 2). Table 1 presents the results of the NICE methodology checklist review. Fourteen systematic reviews were also found and used in this narrative review. Each review followed the Cochrane review or Preferred Reporting Items for Systematic Reviews and Meta-Analyses (PRISMA) guidelines for systematic reviews.

The supplementary Google Scholar search resulted in more than 20,000 citations. Full text appraisal of 27 systematic reviews, 38 narrative reviews, and 52 


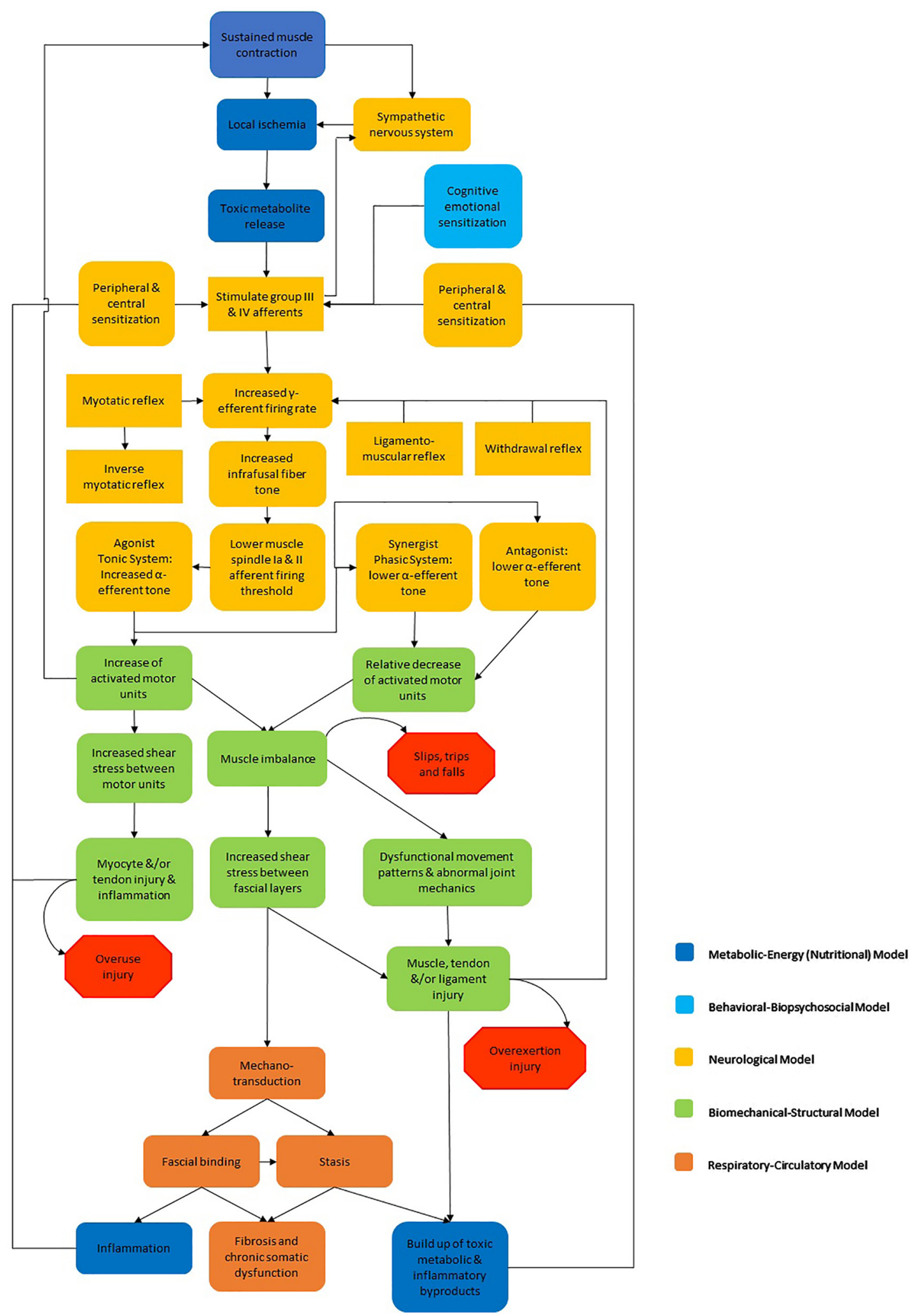

Figure 1: The osteopathic model for developing occupational musculoskeletal disorders is color-coded to indicate interdependent nature of the five models of Osteopathic Care. This model is in a recursive loop where somatic dysfunction produces cellular and tissue injury, worsening dysfunction, leading to more extensive injury. Workers enter the model through mechanisms that activate reflexes that increase gamma-efferent firing rate or because of a predisposition for muscle imbalance. Muscle imbalance leads to abnormal shear stresses, which ultimately injure cells and tissues. Fascial binding occurs, and circulation becomes impaired. Toxic metabolites build and stimulate nociceptors, leading to further gamma-efferent dysfunction, tonic/phasic imbalance, and higher stresses between cells and fascial layers. The cycle continues until functional impairment develops unless its interrupted by external intervention. 
Table 1: Risk of bias per National Institute of Health and Care Excellence methodology checklist for studies used for this review.

\begin{tabular}{|c|c|c|c|c|c|c|}
\hline Study & $\begin{array}{r}\text { Selection } \\
\text { bias }\end{array}$ & $\begin{array}{r}\text { Performance } \\
\text { bias }\end{array}$ & $\begin{array}{r}\text { Attrition } \\
\text { bias }\end{array}$ & $\begin{array}{r}\text { Detection } \\
\text { bias }\end{array}$ & $\begin{array}{r}\text { Overall risk } \\
\text { of bias }\end{array}$ & Conclusions \\
\hline Bruce-Low 2012 [11] & 3 & 3 & 2 & 2 & 2.5 & $\begin{array}{l}\text { One lumbar extension training session per week } \\
\text { is sufficient for strength gains and reductions in } \\
\text { pain in low back pain (LBP). }\end{array}$ \\
\hline Chaléat-Valayer 2016 [12] & 0 & 3 & 0 & 0 & 0.75 & $\begin{array}{l}\text { Not possible to conclude about the effectiveness of } \\
\text { a light exercise program to reduce LBP recurrence } \\
\text { episodes. }\end{array}$ \\
\hline Comper 2017 [13] & 0 & 2 & 0 & 0 & 0.5 & $\begin{array}{l}\text { The job rotation program was not effective in } \\
\text { reducing the number of working hours lost due to } \\
\text { sick leave, decreasing the prevalence of } \\
\text { musculoskeletal symptoms, or improving } \\
\text { perception of musculoskeletal pain and workplace } \\
\text { risk factors, psychosocial risk factors, and } \\
\text { productivity. }\end{array}$ \\
\hline Dahl \& Nilsson 2001 [14] & 2 & 1 & 0 & 2 & 1.25 & $\begin{array}{l}\text { Short-term work site cognitive behavioral therapy } \\
\text { (CBT) program for the prevention of chronic pain } \\
\text { for individuals at risk may be a promising } \\
\text { development in the treatment of pain. }\end{array}$ \\
\hline Esmaeilzadeh 2014 [15] & 0 & 2 & 0 & 0 & 0.5 & $\begin{array}{l}\text { Ergonomic intervention programs may be effective } \\
\text { in reducing ergonomic risk factors among } \\
\text { computer workers, and, consequently, in the } \\
\text { secondary prevention of upper extremity disorders. }\end{array}$ \\
\hline Greene 2005 [16] & 0 & 2 & 0 & 0 & 0.5 & $\begin{array}{l}\text { Participative training in workstation ergonomics } \\
\text { can improve work postures, work practices, risk } \\
\text { factor exposure, and pain. }\end{array}$ \\
\hline Grooten 2007 [17] & 2 & 3 & 2 & 2 & 2.25 & $\begin{array}{l}\text { Ergonomic intervention seemed to be ineffective } \\
\text { for reducing neck/shoulder pain, LBP, and } \\
\text { pain-related disability. }\end{array}$ \\
\hline Harbin 2011 [18] & 0 & 1 & 0 & 2 & 0.75 & $\begin{array}{l}\text { Post-offer physical capacity testing resulted in a } \\
\text { substantial and noticeable decrease in } \\
\text { shoulder-related non-accidental injuries. }\end{array}$ \\
\hline Hill 2011 [19] & 0 & 2 & 0 & 0 & 0.5 & $\begin{array}{l}\text { Stratified approach, by use of prognostic screening } \\
\text { with matched pathways, was associated with a } \\
\text { mean increase in generic health benefit and cost } \\
\text { savings compared with the control group. }\end{array}$ \\
\hline Hill 2016 [20] & 0 & 2 & 0 & 0 & 0.5 & $\begin{array}{l}\text { Modified STarT Back Tool similarly predicts } \\
\text { six-month physical health outcome in other } \\
\text { musculoskeletal pain regions as well as LBP. }\end{array}$ \\
\hline Horneij 2001 [21] & 0 & 2 & 0 & 0 & 0.5 & $\begin{array}{l}\text { Home-care nursing aides were randomly assigned } \\
\text { for: (1) individually designed physical training } \\
\text { program, (2) work-place stress management, (3) } \\
\text { control group. Results revealed no significant } \\
\text { differences between the three groups. }\end{array}$ \\
\hline Jakobsen 2018 [22] & 1 & 1 & 1 & 0 & 0.75 & $\begin{array}{l}\text { Performing supervised group-based exercise at } \\
\text { work and motivational coaching sessions is more } \\
\text { effective than exercising alone at home. }\end{array}$ \\
\hline Járomi 2018 [23] & 0 & 1 & 0 & 0 & 0.25 & $\begin{array}{l}\text { The Spine Care for Nurses program significantly } \\
\text { reduced chronic nonspecific LBP syndrome and } \\
\text { increased the number of properly executed } \\
\text { horizontal and vertical patient lifting techniques in } \\
\text { nurses. }\end{array}$ \\
\hline Jensen 2006 [24] & 1 & 2 & 0 & 2 & 1.25 & $\begin{array}{l}\text { The study showed no effect of a transfer technique } \\
\text { or stress management program targeting LBP. }\end{array}$ \\
\hline Jørgensen 2011 [25] & 0 & 2 & 0 & 0 & 0.5 & $\begin{array}{l}\text { No reduction in musculoskeletal pain, work ability, } \\
\text { sickness, absence from either physical } \\
\text { coordination training, or cognitive behavioral } \\
\text { training compared with the reference group } \\
\text { was found. }\end{array}$ \\
\hline
\end{tabular}


Table 1: (continued)

\begin{tabular}{|c|c|c|c|c|c|c|}
\hline Study & $\begin{array}{r}\text { Selection } \\
\text { bias }\end{array}$ & $\begin{array}{r}\text { Performance } \\
\text { bias }\end{array}$ & $\begin{array}{r}\text { Attrition } \\
\text { bias }\end{array}$ & $\begin{array}{r}\text { Detection } \\
\text { bias }\end{array}$ & $\begin{array}{r}\text { Overall risk } \\
\text { of bias }\end{array}$ & Conclusions \\
\hline Levanon 2012 [26] & 1 & 1 & 0 & 2 & 1 & $\begin{array}{l}\text { The proposed ergonomics interventions effectively } \\
\text { reduced musculoskeletal disorders and improved } \\
\text { body posture for computer users. }\end{array}$ \\
\hline Linton 2005 [27] & 0 & 2 & 1 & 2 & 1.7 & $\begin{array}{l}\text { Adding cognitive-behavioral intervention and } \\
\text { cognitive-behavioral intervention and preventive } \\
\text { physical therapy can enhance the prevention of } \\
\text { long-term disability. }\end{array}$ \\
\hline Menzel 2006 [28] & 0 & 2 & 0 & 2 & 1 & $\begin{array}{l}\text { CBT reduced measures of back pain, stress, and } \\
\text { disability in direct care providers working with } \\
\text { back pain. }\end{array}$ \\
\hline Moreira-Silva 2014 [29] & 1 & 2 & 0 & 2 & 1.25 & $\begin{array}{l}\text { Physical exercise training three times a week } \\
\text { focusing on stretching exercises and general } \\
\text { strength reduced pain and related symptoms in } \\
\text { factory workers. }\end{array}$ \\
\hline Rantonen 2018 [30] & 0 & 2 & 0 & 0 & 0.5 & $\begin{array}{l}\text { No differences between multidisciplinary } \\
\text { rehabilitation, progressive exercise, and control } \\
\text { groups for decreased low back pain and physical } \\
\text { impairment or sickness absence. }\end{array}$ \\
\hline Rantonen 2012 [31] & 0 & 2 & 0 & 0 & 0.5 & $\begin{array}{l}\text { Among employees with mild LBP, both rehabilitation } \\
\text { and exercise reduced pain, but the effects on } \\
\text { sick-absences and physical impairment were minor. }\end{array}$ \\
\hline Rasotto 2015 [32] & 1 & 1 & 2 & 0 & 1 & $\begin{array}{l}\text { A workplace exercise protocol reduced pain } \\
\text { symptoms on neck, shoulders, elbows, and wrists. } \\
\text { Grip strength and upper-limb mobility improved } \\
\text { as well. }\end{array}$ \\
\hline Rasotto 2015b [33] & 0 & 1 & 0 & 0 & 0.25 & $\begin{array}{l}\text { A workplace exercise protocol in female workers } \\
\text { at moderate risk for work-related MSK disorders, } \\
\text { showed reductions of upper limb and neck pain } \\
\text { and disability. }\end{array}$ \\
\hline Rempel 2006 [34] & 0 & 2 & 0 & 2 & 1 & $\begin{array}{l}\text { Providing a large forearm support with ergonomic } \\
\text { training prevented upper body MSK disorders and } \\
\text { reduced upper body pain associated with } \\
\text { computer work. }\end{array}$ \\
\hline Robertson 2003 [35] & 3 & 3 & 2 & 2 & 2.5 & $\begin{array}{l}\text { Self-reported work-related MSK disorders } \\
\text { decreased for the group who had a workplace } \\
\text { change and ergonomic training relative to a } \\
\text { workplace change-only group and a no intervention } \\
\text { control group. }\end{array}$ \\
\hline Shiri 2011 [36] & 0 & 2 & 1 & 2 & 1.25 & $\begin{array}{l}\text { Pain intensity, pain interference with work, leisure } \\
\text { time, or sleep did not differ between the ergonomic } \\
\text { improvement and control groups during the } \\
\text { one-year follow-up. However, early ergonomic } \\
\text { intervention reduced sickness absence due to } \\
\text { upper-extremity or other MSK disorders. }\end{array}$ \\
\hline Sjögren 2006 [37] & 0 & 1 & 1 & 0 & 0.5 & $\begin{array}{l}\text { A physical exercise intervention, which included } \\
\text { daily light resistance training, conducted during } \\
\text { the working day affected low back symptoms in a } \\
\text { positive direction among symptomatic office workers. }\end{array}$ \\
\hline Sundstrup 2014 [38] & 0 & 1 & 0 & 0 & 0.25 & $\begin{array}{l}\text { Resistance training at the workplace results in } \\
\text { improvements in pain, disability, and muscle } \\
\text { strength in adults with upper limb chronic pain } \\
\text { doing highly repetitive and forceful manual work. }\end{array}$ \\
\hline Tunwattanapong 2016 [39] & 0 & 1 & 1 & 0 & 0.5 & $\begin{array}{l}\text { A regular stretching program performed for four } \\
\text { weeks can decrease neck and shoulder pain and } \\
\text { improve neck function and quality of life for office } \\
\text { workers who have chronic moderate-to-severe neck } \\
\text { or shoulder pain }\end{array}$ \\
\hline
\end{tabular}


Table 1: (continued)

\begin{tabular}{|c|c|c|c|c|c|c|}
\hline Study & $\begin{array}{r}\text { Selection } \\
\text { bias }\end{array}$ & $\begin{array}{r}\text { Performance } \\
\text { bias }\end{array}$ & $\begin{array}{r}\text { Attrition } \\
\text { bias }\end{array}$ & $\begin{array}{r}\text { Detection } \\
\text { bias }\end{array}$ & $\begin{array}{r}\text { Overall risk } \\
\text { of bias }\end{array}$ & Conclusions \\
\hline Yassi 2001 [40] & 1 & 1 & 0 & 2 & 1 & $\begin{array}{l}\text { Combined training with assured availability of } \\
\text { mechanical and other assistive patient handling } \\
\text { equipment improved comfort with patient handling, } \\
\text { decreased staff fatigue, and decreased physical } \\
\text { demands. However, injury rates were not } \\
\text { significantly reduced. }\end{array}$ \\
\hline
\end{tabular}

Table 2: Level of evidence for preventive interventions having a positive effect on targeted vulnerabilities for work-related musculoskeletal injury.

\begin{tabular}{|c|c|c|c|}
\hline $\begin{array}{l}\text { Model of osteopathic } \\
\text { care }\end{array}$ & Targeted vulnerabilities & Intervention (level, s) ${ }^{\mathbf{a}}$ & $\begin{array}{l}\text { Highest level } \\
\text { of evidence }^{b}\end{array}$ \\
\hline \multirow[t]{7}{*}{ Biomechanical } & Demands exceed capacity & $\begin{array}{l}\text { Job-specific preplacement physical } \\
\text { examinations (1) [47] }\end{array}$ & $2 \mathrm{~A}$ \\
\hline & & Physical ability testing $(1)[18,87]$ & $1 \mathrm{~A}$ \\
\hline & & Assign restriction $(1,2,3)[88]$ & 5 \\
\hline & & Job rotation $(1,2)[50]$ & $2 \mathrm{~A}$ \\
\hline & & $\begin{array}{l}\text { Workplace strength training }(1,2)[22,29,32,33 \text {, } \\
37,38,51]\end{array}$ & $1 \mathrm{~B}$ \\
\hline & Biomechanical stress & Ergonomic interventions $^{c}(1,2)[15,16,26,34]$ & $1 \mathrm{~B}$ \\
\hline & Dysfunctional motion patterns & Janda approach $(1,2,3)[7]$ & 5 \\
\hline \multirow[t]{8}{*}{ Neurological } & Proprioceptive deficit & Janda approach $(1,2,3)[7]$ & \\
\hline & Alpha-gamma imbalance & Counterstrain $(1,2,3)[70]$ & $2 B$ \\
\hline & Tonic-phasic imbalance & Janda approach $(1,2,3)[7]$ & 5 \\
\hline & & Strength training $(1,2)[29,32,33,37,38,51]$ & $1 \mathrm{~B}$ \\
\hline & & Stretching program $(1,2)[65]$ & $1 \mathrm{~A}$ \\
\hline & Autonomic dysfunction & $\begin{array}{l}\text { Rib raising technique/paraspinal inhibition }(1,2 \text {, } \\
\text { 3) [69] }\end{array}$ & $2 \mathrm{~B}$ \\
\hline & & $\begin{array}{l}\text { Cranial osteopathic manipulative medicine } \\
(1,2,3)[67]\end{array}$ & $1 \mathrm{~B}$ \\
\hline & & Balanced ligamentous tension $(1,2,3)[67]$ & $1 \mathrm{~B}$ \\
\hline \multirow[t]{6}{*}{ Metabolic-energy } & Poor diet & Dietary Guidelines for Americans [89] & $2 \mathrm{~B}$ \\
\hline & & $\begin{array}{l}\text { Nutritional supplements for susceptible groups } \\
\text { [90-92] }\end{array}$ & $2 \mathrm{~A}$ \\
\hline & Fatigability & Physical ability testing (1) [87] & $1 \mathrm{~A}$ \\
\hline & & Assign limitations $(1,2,3)[88]$ & 5 \\
\hline & Comorbidities & Health insurance coverage & 5 \\
\hline & Smoking & Multi-component intervention [97] & $2 \mathrm{~A}$ \\
\hline \multirow[t]{6}{*}{ Respiratory-circulatory } & Stasis of toxic metabolites & Myofascial release $(2,3)[99]$ & 5 \\
\hline & & Lymphatic pump $(2,3)[121]$ & 5 \\
\hline & Fascial binding & Myofascial release $(2,3)[102]$ & $1 \mathrm{~A}$ \\
\hline & Local hypoxia & Myofascial release $(2,3)[99]$ & 5 \\
\hline & & $\begin{array}{l}\text { Rib raising technique/paraspinal inhibition (1, } 2 \text {, } \\
\text { 3) [69] }\end{array}$ & $2 B$ \\
\hline & & Counterstrain $(1,2,3)[70]$ & $2 B$ \\
\hline \multirow[t]{8}{*}{ Behavioral-biopsychosocial } & Mental health disorders & Cognitive behavioral therapy $(1,2,3)[112]$ & $1 \mathrm{~A}$ \\
\hline & & Employee assistance program $(2,3)$ & 5 \\
\hline & Cognitive distortions & Cognitive behavioral therapy $(1,2,3)$ & $1 \mathrm{~A}$ \\
\hline & & {$[14,28,112]$} & \\
\hline & & STarT-Back/MSK $(3)[19,20]$ & $2 \mathrm{~B}$ \\
\hline & & Neurophysiology of pain education $(2,3)[114]$ & $1 \mathrm{~B}$ \\
\hline & Low supervisor support & Supervisor training & 5 \\
\hline & $\begin{array}{l}\text { Complex workers' } \\
\text { compensation system }\end{array}$ & Workers' compensation liaison & \\
\hline
\end{tabular}

\footnotetext{
${ }^{\mathrm{a}} 1$ =primary prevention; $2=$ secondary prevention; $3=$ tertiary prevention. ${ }^{\mathrm{b}}$ Oxford University Centre for Evidence Based Medicine. ${ }^{\mathrm{c}}$ Evidence for
} office work/computer workstations/sedentary duty only. 


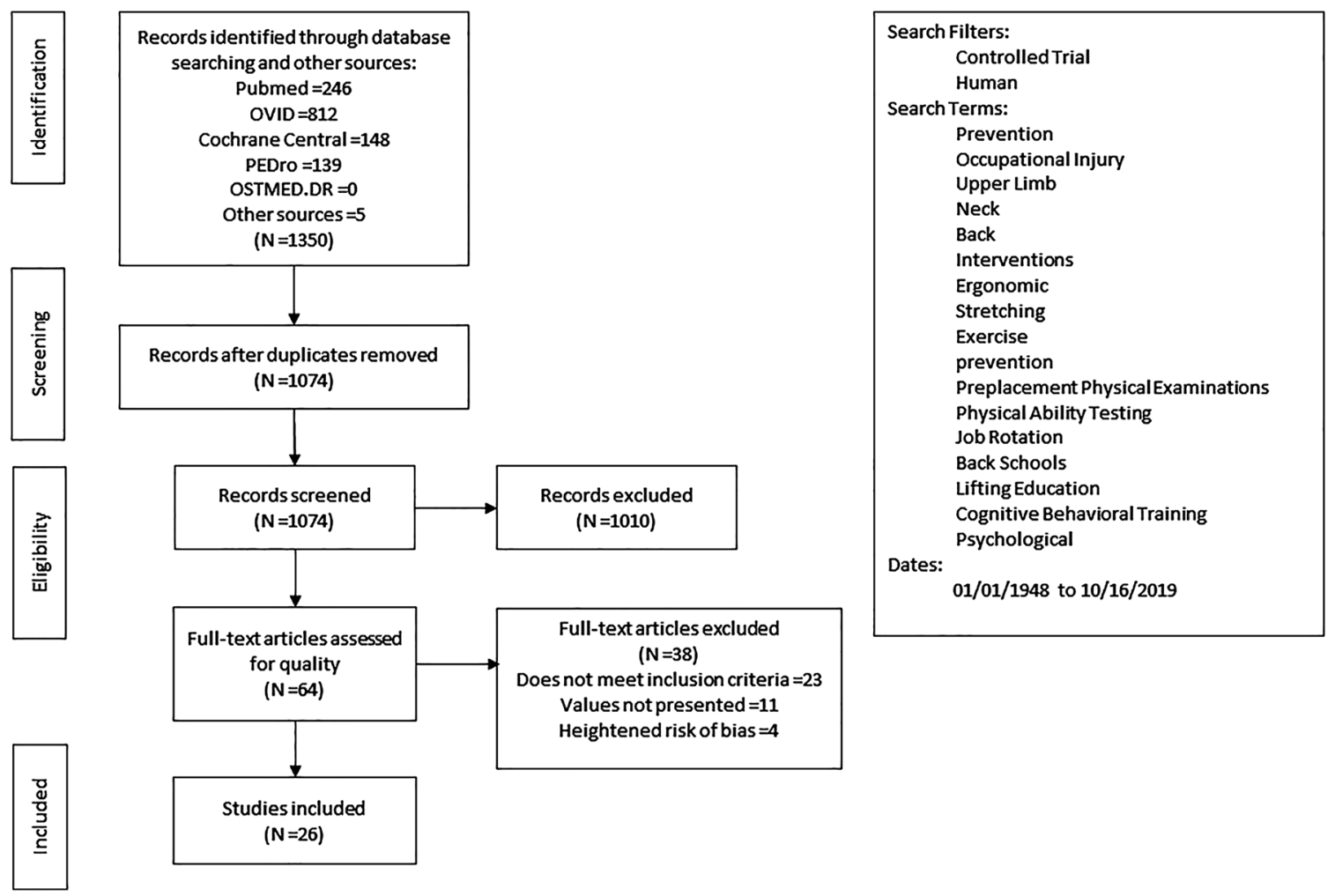

Figure 2: An overview of the identification, screening, eligibility, and inclusion process for this literature review.

nonclinical studies was completed. From these references, three systematic reviews, 13 narrative reviews, and 15 nonclinical studies were used in this review.

\section{Biomechanical-structural model}

\section{Pathophysiology}

The biomechanical-structural model views health from the perspective of the musculoskeletal system and its interconnected groups of bones, muscles, ligaments, tendons, and fascia. Disturbances of the musculoskeletal system result in spinal reflex disturbances and subsequent dysfunction of somatic and visceral structures which lead to morbidity [41].

Poor ergonomic design of the work environment leads to awkward movements and postures that place biomechanical stresses on joints, muscles, and tendons. Injury occurs when demands are placed upon tissues that are greater than the tissue's structural or physiological capacity to meet the demands. The incidence of occupational injuries is related to physically demanding factors, including substantial physical exertion, lifting or carrying more than $10 \mathrm{lbs}$, using stairs and inclines, kneeling or crouching, and reaching [4]. These risk factors reflect ergonomic stresses resulting from prolonged or awkward postures, repetition without adequate recovery time, or the requirement to lift or move excessive loads. Some ergonomic stressors bring soft tissues into proximity of bone, leading to friction and inflammation, and others place undue strain on muscles and connective tissues $[5,7]$. Baseline postural abnormalities and dysfunctional movement patterns likely predispose the worker to these effects.

When muscles are used in unsuitable ergonomic environments, additional motor units must be activated to maintain strength, which begins within the first minute of a contraction, particularly with a fatiguing effort [42]. Tonic muscles are more susceptible to motor unit recruitment than phasic muscles [42]. Abnormal shear stress develops between newly recruited motor-units and adjacent motorunits. Eventually, shear transmission leads to myocyte damage as the muscle continues working despite fatigue or somatic dysfunction [5]. This process impairs movement patterns and joint mechanics.

Dysfunctional movement patterns and altered joint mechanics increase the physical strain exerted on tendons and often place tendons against the abrading surface of adjacent bone [7]. Tendon straining results in fiber deformation [43]. The collagen fibers become more parallel as strain increases, slide adjacent to one another, and 
generate shear forces [43]. The tendon will recoil back to its original conformation when unloaded if the strain stays below 4\%; strains of 4-8\% result in microscopic failure, and strains of $8-10 \%$ result in macroscopic failure [43].

Microtrauma within tendons may also result from nonuniform stresses produced by changing motor unit activation patterns. Nonuniform stress creates regions of excessive loading in the substance of the tendon and excessive shear forces between adjacent fibrils. Accrued microinjuries result in steady deterioration in the quality of the tendon matrix [44]. Transformation of the tendon matrix from organized type I collagen fibrils to randomly organized, small diameter fibrils containing type I and type II collagen follows; these changes bring about tendinopathy [44]. Some workers have medical comorbidities, such as Ehlers-Danlos syndrome, diabetes, and rheumatoid arthritis, that make their tendons more vulnerable to this process [45].

Dysfunctional joint mechanics also increase the load exerted on some ligaments, and with the application of a constant load, fascia and ligaments lengthen, or creep, because of disrupted crosslinks within the collagen fiber matrix of fascia and ligaments [6, 41]. There is less capacity for creep to occur without significant damage in ligaments relative to other myofascial structure because of the relative rigidity necessary for ligamentous function. Therefore, ligamentous creep is associated with declining ligamentous tension, subsequent joint laxity, reduced stability, corrupted afferent signals, and increased injury risk. High frequency repetitive motion tasks produce a significant degree of creep requiring extended recovery periods. There is a risk of creep accumulating from one day to the next if recovery is incomplete, which leaves the worker predisposed to injury [6]. Workers with benign joint hypermobility syndrome, Marfan syndrome, and Ehlers-Danlos syndrome are especially vulnerable to this effect [7].

\section{Interventions}

To mitigate these processes, one must attempt to achieve the best possible interface between the worker and the work environment. Preplacement physical examinations are a primary prevention intervention meant to determine a new hire's capacity to meet the demands of the job and to identify any disorders or medications that may place the employee at risk for injury [46]. Studies investigating preplacement examinations have been too heterogeneous for statistical pooling of results, and the quality of the evidence for all outcomes is very low [46]. However, a Cochrane review supports the use of job-specific preplacement examinations [47].
Another primary prevention intervention is a workplace ergonomic program. Many employers use systematic ergonomic improvement processes to remove risk factors that could lead to musculoskeletal injuries with the goal of improving employee performance and productivity. However, except for office environments and computer workstations, evidence supporting the effectiveness of ergonomic interventions is inconclusive [15, 16, 26, 34, 48]. Ergonomic assessments are best used in conjunction with job-matching processes.

Education programs attempt to mitigate the risk of work-related back injuries by increasing the participant's knowledge, thereby altering the individual's behaviors to mitigate biomechanical risk. These programs typically cover anatomy, biomechanics, lifting, postural changes, and home exercises [48]. However, a systematic review [48] and metaanalysis [49] presented strong and consistent evidence that education alone does not seem to prevent back pain and comprehensive "back schools" are not effective in preventing neck and back pain.

Job-rotation programs are often recommended as a primary and secondary prevention measure to mitigate continuous exposure to risk factors for musculoskeletal disorders. In terms of risk control, job rotation is defined as a strategy for rotating workers between tasks with different physical demands to avoid overloading specific body parts [50]. Currently, only weak evidence supports job rotation as a strategy for the prevention and control of musculoskeletal disorders, and although it does not appear to reduce the exposure of physical risk factors, there are positive correlations between job rotation and higher job satisfaction $[13,50]$.

Strength training is gaining acceptance as a primary and secondary prevention intervention [22, 29, 32, 33, 37]. It appears that implementation of strength training at the workplace not only prevents deterioration of work ability among manual workers with chronic pain, but also bolsters mental resources and improves perceptions of work demands [38]. A 2016 systematic review [51] found strong evidence for using resistance training for the prevention of work related upper extremity injuries resulting from sedentary work. Physical therapists could work with supervisors to develop strength training programs that harden workers to their duties and maintain balance between tonic and phasic musculature.

Shoe inserts and lumbar supports have been used to align and support the musculoskeletal system to decrease demands placed upon tissues with the hope of preventing musculoskeletal pain and injuries. However, evidence from systematic reviews $[49,52]$ suggests that shoe insoles do not prevent low back pain. There is moderate evidence 
that lumbar supports are no more effective than no intervention or lifting training in preventing low back pain. There is conflicting evidence for lumbar supports being effective supplements to other preventive interventions [53]. Furthermore, National Institute of Occupational Safety and Health has asserted that there is insufficient evidence to support the use of lumbar supports as a primary prevention measure [54]. These findings are not unexpected as they do nothing to improve muscle strength, muscle endurance, or joint mechanics.

Osteopathic manipulative treatment (OMT) may be used for primary prevention by optimizing workers' musculoskeletal system, secondary injury prevention as part of an early symptom intervention program, or tertiary prevention as a component of a comprehensive injury management program [41]. According to this model, the goals of the OMT techniques are to restore balanced posture and efficient function of musculoskeletal components. These goals may be accomplished using high-velocity, low-amplitude, muscle energy, counterstrain, myofascial release, ligamentous articular techniques, and functional techniques [41].

Any identified muscle imbalance syndromes should be managed to maintain functional homeostasis. The Janda approach to treatment of muscle imbalance follows a three-step process: (1) normalization of the peripheral structures using the techniques noted above, (2) restoration of balance between the tonic and phasic muscle systems, and (3) balance and coordination training [7].

\section{Neurological model}

\section{Pathophysiology}

The neurologic model considers how autonomic equilibrium, neural reflex activity, segment facilitation, afferent nerve signals, and nociception contribute to injury and disease. With the neurological model, the physician considers the function of the patient's central and peripheral nervous system, including both the somatic and autonomic components [9]. The implications of this model are particularly significant for workers with preexisting proprioceptive deficits, peripheral sensitization, central sensitization, autonomic dysfunction, or fibromyalgia.

Musculoskeletal disorders occur when the demands of work exceed the strength or endurance of the worker. The disparity between demands and capacity produce abnormal tissue stresses, early fatigue, and muscular imbalances [7]. Consequently, one of the body's inherent reflexes will eventually activate as a protective response known as the myotatic reflex, the inverse myotatic reflex, the withdrawal reflex, and the ligamento-muscular reflex [55]. The reflexes send information to the spinal cord where the signal is processed, and a response is generated. Except for the inverse myotatic reflex, the descending systems respond by facilitating both alpha- and gamma-efferent neurons to provoke a protective action [55]. Coactivation of alpha- and gammaefferents helps to maximize the protective response by contracting the muscle and increasing its sensitivity to stretch [55]. These reflexes are normally fleeting; however, when they persist, they produce somatic dysfunction. Somatic dysfunction is impaired or altered function of skeletal, arthrodial, and myofascial structures, along with associated vascular, lymphatic, and neural elements. Somatic dysfunctions produce tissues texture changes, positional asymmetry, motion restriction, and tenderness, which are amendable to OMT [41].

There is normally a balance between reflex habituation and sensitization with repetitive stimulation; however, this balance is disrupted when inflammation is present. The normal dampening effects of habituation shift toward sensitization, which is a state of subthreshold excitation that requires less afferent stimulation to trigger a reflex response [55]. Sensitization is also known as spinal facilitation, and long-term sensitization begins if sensitization continues for several minutes. If the stimulus endures, spinal fixation will begin to develop. Nociceptive input for as little as 20-45 minutes may produce increased reflex sensitivity for three or more weeks [55]. Peripheral inflammation causes some spinal cord microglial cells to begin expressing proinflammatory cytokines including interleukin- $1 \beta$ and tumor necrosis factor- $\alpha$, which facilitate excitatory pain circuits and impede inhibitory pain circuits [56]. This process produces hyperalgesia and allodynia. Referred pain and hyperalgesia may ultimately cross multiple spinal segments as the cytokines diffuse to neighboring spinal levels [57]. Once fixation is well established, interneurons die by a process that primarily affects the inhibitory interneurons, often replacing them with excitatory interneurons. These spinal reflex pathways may be left in state of permanent excitability, responding to all input in an exaggerated fashion, which increases the neuron drive to the associated somatic and visceral structures [55].

Not all muscles react in the same manner-tonic and phasic muscles work synergistically. Tonic muscles are the prime movers or agonists and are prone to hypertonicity and shortening [7]. Phasic muscles are the synergists that work with the agonist to produce movement or stabilization around a joint, and they may be secondary movers, stabilizers, or neutralizers [7]. The synergistic interactions of tonic and phasic muscles assure balanced movement 
patterns. Phasic muscles have a propensity for lengthening and becoming hypotonic. Due to high-frequency firing of gamma-efferent neurons, the small alpha-motoneurons of tonic muscles respond to stretch by discharging for much longer duration relative to the large alpha-motoneurons innervating phasic muscles [58]. This action suggests that a tonic muscle will respond more readily to stretch and become more hypertonic than its phasic synergist.

The relationship between muscle length and spindle firing rate is used by the central nervous system to gauge position [59], which requires the spindle fibers to remain passive with no fusimotor activity [60]. With somatic dysfunction, the fusimotor system is activated [55]. This activation impairs position sense, alters movement patterns and affects biomechanics [61-64]. The impaired joint mechanics stress the area of the tendon commonly affected by tendinopathy [8].

The musculoskeletal system receives sympathetic innervation and receives no parasympathetic innervation. Muscle hypertonicity and nociception activate afferents and stimulate the sympathetic nervous system. This affects functional changes of the associated vascular structures and results in vasoconstriction with decreased oxygen and nutrient delivery, and subsequent tissue texture changes [55].

\section{Interventions}

Preshift stretching sessions are commonly used in workplaces for primary prevention of injuries by lengthening hypertonic muscle and reducing resting tone $[39,48,65]$. However, stretching may produce creep and tendon deformation, and reduce muscle force generation [43]. A previous systematic review [65] provided mixed findings but demonstrated some limited beneficial effect of stretching in preventing work-related musculoskeletal disorders for occupations not requiring heavy exertion. Therefore, stretching programs should be limited to occupations that are sedentary, such as office work and data entry [39]. This may be related to which muscles are being stretched relative to which muscles are being over- or underutilized. When phasic muscles are stretched, they lengthen and become more hypotonic, which results in further muscle imbalance, performance declination, and greater risk of injury [7]. However, tonic muscles become less hypertonic when stretched, restoring muscle balance [7].

OMT is directed at restoring normal muscle function and joint mobility to reduce the level of afferent input to the spinal cord and brain [66], and it is also used to restore autonomic balance [55]. The OMT techniques used for this domain of worker health include counterstrain, cranial osteopathic manipulative medicine, paraspinal inhibition, rib raising, and progressive inhibition of neurological structures [41].

Balanced ligamentous tension, balanced membranous tension, and craniosacral techniques can influence autonomic nervous system activity by increasing parasympathetic function and decreasing sympathetic activity, compared with sham therapy and control group [67]. The compression of the fourth ventricle (CV-4) technique has been shown to lower the tone of the sympathetic nervous system and enhance fluid exchange [68]. Rib raising is believed to temper sympathetic nervous system activity by activating the thoracic sympathetic chain ganglia adjacent to the costotransverse articulation [69], while counterstain has been shown to decrease the amplitude of the stretch reflex [70].

\section{Metabolic-energy (nutritional) model}

\section{Pathophysiology}

In industry, effective injury reduction programs should go beyond traditional methods of job-related ergonomic risk factors and address factors that appear to decrease capacity, including smoking, nutrition, and body weight. The metabolic-energy (nutritional) model addresses the need for homeostatic balance between the body's energy reserves and the energy demands [9]. The goal of the metabolic-energy (nutritional) model is to optimize self-regulatory and self-healing mechanisms by promoting balanced energy expenditure and exchange, which augments cellular, tissue, and organ functions [9]. This is achieved through nutritional counseling, diet, and exercise advice [9, 41]. According to this model, any factor (e.g., advanced age, poor nutrition, smoking, and obesity) that limits a person's physiologic reserves will increase their risk of injury, delayed recovery, impairment, and disability [9]. Certain medications such as anticholinergics, alpha-agonists, and anticonvulsants decrease one's physiologic reserve by impairing fatigue resistance and coordination [71]. Preexisting physical deconditioning, muscular imbalance, physical impairment, pain, and medical comorbidities are also known to lower physiologic resources and leave workers susceptible to the effects of fatigue [72-75].

Muscle fatigue leaves workers vulnerable to overuse and overexertion injury, as well as slips, trips, and falls [72-75]. Reduced oxygen availability lessens the recruitment of fatigue-resistant type I (slow-twitch) muscle fibers. Consequently, more type II (fast-twitch) muscle fibers need to be activated under hypoxemic conditions to maintain a 
constant workload. Type II muscle fibers are associated with an increased rate of metabolite accumulation and fatigue development compared with type I muscle fibers $[76,77]$.

Phasic muscles have a greater proportion of type II fibers, which are high in glycolytic enzymes and myosin ATPase activity and depend on anaerobic metabolism [78]. Consequently, these muscles fatigue rapidly and respond to irritation by weakening; this weakening is a significant problem that produces muscular imbalance associated with abnormal joint mechanics and early fatigue [78]. Preexisting muscle imbalances increase a worker's susceptibility to this effect. Phasic muscles must work harder to compensate for dysfunctional tonic muscle to maintain proper movement patterns [79]. As the phasic muscles fatigue, ability to compensate is lost and injury ensues.

Calcium accumulates with sustained muscle use and degrades cell membrane proteins by activation of protease calpain, which leads to calcium influx, leakage of lactate dehydrogenase, and cell death $[5,80]$. Dead and damaged cells release endogenous proteins called damage-associated molecular patterns, which bind to the nucleotide binding domain and leucine-rich-repeat-containing receptors within monocytes, macrophages, and dendritic cells [81]. This process activates proinflammatory pathways that produce inflammatory mediators, and bradykinin, prostaglandin E2, and serotonin are liberated and sensitize group IV nociceptors [82, 83]. Nociceptor stimulation disrupts alphaand gamma-efferent homeostasis further.

These inflammatory mediators act upon the vasculature and result in vasodilation and increased vascular permeability [84]. Excessive accumulation of interstitial fluid is deleterious to tissue function [84]. The formation of edema increases the diffusion distance of oxygen and nutrients, and it also limits the diffusion and clearance of toxic byproducts of cellular metabolism [84]. This leads to poor nutritional support and waste clearance for the innermost cells of the involved capillary bed, and the vitality of these cells rapidly declines [84]. This effect is accelerated by poor baseline nutritional status, and plasma proteins accumulate in the area and trigger chronic inflammation, fibrosis, and dysfunction if they remain stagnant [85]. Pain develops as prostaglandins and nitrogenous waste builds up. Group III and group IV nociceptors are stimulated, and gammaefferent firing rate is increased [83]. Functional impairment and disability may result if the cycle of dysfunction continues uninterrupted.

\section{Interventions}

There are many significant cofactors for workplace injuries that cannot be accounted by through ergonomic factors or employee characteristics such as aging, medical history, and physical impairments. Preplacement physical ability testing (PAT) was first implemented during World War II to meet this shortfall [86]. These tests are intended to measure a new hire's physical capacity and fatigue resistance. Occupational injuries decrease significantly when the results of a well-designed PAT are compared with the job requirements to identify limitations and to assign restrictions for the purpose of job matching [18]. A meta-analysis [87] of the three predictive validation studies of pre- and post-implementation of a physical ability test battery were performed at 175 locations in different industries including food distribution, soft drink distribution, and retail distribution. These studies covered a total of more than 21 million worker-hours pre- and post-implementation. The findings indicated that newly hired employees who passed a battery of strength and endurance tests based on ergonomic analysis had a $47 \%$ lower relative worker compensation injury rate $(\alpha<0.001)$ and $21 \%$ higher relative retention $(\alpha<0.05)$ [87].

More energy is required to work with an injury, and it is diverted away from healing to meet the demands of continued activity [9]. Work restrictions based on knowledge of the workers' duties are an important component of secondary and tertiary prevention programs for work-related injuries and the maintenance of energy homeostasis. Risk, capacity, and tolerance must be considered to return a patient to work after injury [88]. Risk is the chance of incurred harm to the patient or public if specific work tasks are undertaken, and it is the reason for physician-imposed restrictions concerning what the injured worker should not do [88]. Capacity refers to measurable limits of strength, flexibility, and endurance; if needed, objective measurement of strength, flexibility, and endurance can be gathered with a functional capacity evaluation. A capacity deficit is a reason for physician-described limitations for the injured worker [88]. Tolerance is a psychological concept and not quantifiable; it describes what the employee is willing to do. Brief physician-imposed restrictions may be appropriate for acute injuries. However, long-term physician directed restrictions or limitations may lead to iatrogenic disability [88].

Nutritious foods supply the building blocks needed to recover from an injury. The 2015-2020 Dietary Guidelines for Americans [89] advise following a healthy eating pattern across one's life span. These guidelines can help workers understand how they should eat to maximize the recovery process and focuses on eating a variety of foods, while limiting calories from added sugars and saturated fats and reducing sodium intake [89]. A healthy eating pattern includes a variety of vegetables from all the subgroups, including those that are dark green, red, or orange; legumes; and starchy tubers. Whole fruits and grains, fat- 
free or low-fat dairy (including milk, yogurt, cheese) and fortified soy beverages are recommended. The recommended protein sources are seafood, lean meats and poultry, eggs, legumes, nuts, seeds, and soy products. A healthy eating pattern limits saturated fats and trans fats, added sugars, and sodium.

The triage theory suggests that modest micronutrient deficiencies induce reallocation of nutrients to processes necessary for immediate survival at the expense of longterm health. Certain groups, such as patients who are obese, are susceptible to nutrient deficiencies that may impair healing and delay recovery and increase the risk of developing chronic medical conditions. Most vitamins are deficient in patients who are obese, particularly the fatsoluble vitamins, folic acid, vitamin B12, and vitamin C [90]. Gastric bypass surgery often leads to the malabsorption of nutrients and subsequent nutritional deficiencies. The most common deficiencies are vitamin B12, folate, zinc, iron, copper, calcium, and vitamin D [91]. Vegan diets are growing in popularity for many reasons. However, people following a vegan diet are at risk for deficiencies in vitamin B12, iron, calcium, vitamin D, omega-3 fatty acids, and protein [92]. Patients in these categories should have their micronutrient levels monitored annually and supplementation provided if indicated.

From 2014 to 2016, 15.5\% of working adults in the United States were current tobacco smokers [93]. Smoking cessation interventions should be included in each level of injury prevention. Smoking appears to lower the threshold of fatigue, while reducing maximal aerobic capacity [94]. Furthermore, smoking reduces parasympathetic nerve activity and activates sympathetic cardiac control [94]. There is also evidence of adverse effects on intervertebral discs, muscles, tendons, cartilage, and ligaments [95]. Clinical and experimental studies have revealed that smoking-induced skeletal muscle damage is due to impaired muscle metabolism, increased inflammation and oxidative stress, overexpression of atrophy related genes and activation of various intracellular signaling pathways. Besides a reduction of the muscle mass and strength, smoking is also associated with a higher risk of muscle pain. There is a positive relationship between the daily mean number of cigarettes, the total number of cigarettes smoked in life, and the severity of rotator cuff tears. Smoking is also a strong risk factor for distal biceps tendon rupture; smokers have a 7.5 times greater risk of distal biceps tendon rupture compared with nonsmokers [96]. Occupational medicine physicians are encouraged to screen all injured workers for tobacco use, offer smoking cessation counseling, and provide pharmacotherapy when appropriate [97].

\section{Respiratory-circulatory model}

\section{Pathophysiology}

The respiratory-circulatory model considers the role played by the circulation of blood and lymph through the body to maintain extracellular and intracellular environments by delivering oxygen and nutrition, while removing metabolic waste [9, 41]. Cardiac disease, respiratory disease, peripheral vascular disease, venous insufficiency, and musculoskeletal dysfunction interfere with the respiratory-circulatory function, thereby increasing the potential for developing disease and delaying recovery from injury.

Cells need a relatively constant and favorable environment to produce the energy needed for normal function. Circulation is the cell's connection to the rest of the body, delivering the required nutrients and removing metabolic waste products. Intramuscular pressures near activated motor units often exceed systemic blood pressure compressing small blood vessels, producing local hypoxia. Upon reperfusion, free radicals damage the skeletal muscle membrane and impair sarcoplasmic reticulum ion pump function [5]. Blood vessels also constrict in response to the increase in sympathetic tone, which aggravates local hypoxia. Exaggerated sympathetic outflow is harmful if it remains unchecked, and prolonged vasoconstriction leads to tissue ischemia and pain, further increasing the sympathetic tone and impairing recovery [55].

The extracellular matrix is an acellular three-dimensional macromolecular network composed of collagens, proteoglycans, glycosaminoglycans, elastin, fibronectin, laminins, and several other glycoproteins. This matrix organizes cells and provides them with environmental signals that direct site-specific cellular regulation [85]. Local inflammation leads to the formation of reactive oxygen and nitrogen species, and the release of hydrolytic enzymes. These substances destroy extracellular matrix proteins. This alters the compliance characteristics of extracellular matrix gel state such that interstitial pressure fails to increase as edema forms. Excessive accumulation of interstitial fluid is deleterious to tissue function as the diffusion and clearance of toxic byproducts of cellular metabolism is impeded [84]. The vitality of neighboring cells decline as they fail to get nutrition and waste accumulates; pain will be apparent as prostaglandins and nitrogenous waste builds up and local hypoxia develops [84].

Edema also creates undue fascial stress that causes the extracellular matrix to exert force upon fibroblasts [98]. Mechanotransduction induces changes within the fibroblast nucleus, altering gene expression [98]. Some fibroblasts 
differentiate into myofibroblasts, which have contractile properties and produce prestress within the fascia and fascial binding ensues [98]. Fascial binding disrupts the fluid channels of the interstitial space. Anchoring filaments, which attach to lymphatic endothelial cells to facilitate lymphatic filling, lose their mechanical integrity and more fluid accumulates [84]. If fascial distortions persist, fibrotic changes occur, and chronic motion restriction develops.

\section{Interventions}

Management is aimed at restoring normal mechanics of the thoracic spine and rib cage and improving movement of the transverse diaphragms. The OMT techniques used in this model are osteopathic cranial manipulative medicine, ligamentous articular strain, myofascial release, and lymphatic pump techniques [41]. Counterstrain may improve local circulation and result in improved delivery of nutrients, increased removal of metabolic waste, and reduced swelling [99]. These techniques are usually performed after treating any somatic dysfunctions of the spinal transition zones. Transition zones are areas susceptible to somatic dysfunction and biomechanical stress which lead to fascial binding and impaired diaphragmatic function. Dysfunction in these regions will result in alterations of the pressure gradients between the zones, adversely affecting the respiratory pumping mechanism, and the venous and lymphatic circulation [100].

Brief stretching of the fascia decreases transforming growth factor- $\beta 1$ mediated fibrinogenesis and is a likely mechanism of action for myofascial release technique [101]. A systematic review by Ajimsha et al. [102] assessed the quality, results, and limitations of 19 RCTs. Myofascial release was demonstrated to be equal to or more effective than sham, conventional, and no treatment for various musculoskel etal and painful conditions. The authors concluded that myofascial release may be useful as either a sole therapy or as an adjunct therapy for a variety of musculoskeletal conditions, such as subacute low back pain, fibromyalgia, lateral epicondylitis, and plantar fasciitis [102].

\section{Behavioral-psychosocial model}

\section{Pathophysiology}

The goal of the behavioral-psychosocial model is to improve the psychological and social elements of overall health [41]. This model recognizes that patient outcomes are strongly influenced by the patient's perception of the environmental and psychological context of the primary complaint.

The psychological risk factors for injury and disability include dysfunctional aspects of thoughts, feelings, and behaviors that are barriers to achieving homeostasis. Social risk factors are exogenous stressors, such as lack of job control, low supervisor support, and complexity of the workers' compensation system. These stressors are barriers to recovery for individuals that rely on passive coping strategies. Passive coping strategies, such as avoidance, suppression, rumination, and habitual motivation are associated with dysfunctional health behaviors and impaired recovery from injury [103, 104]. For example, passive coping strategies my lead to nonadherence to ergonomic measures, failing to exercise, continuing to smoking, and failing to follow dietary recommendations.

Fear-avoidance beliefs and behaviors, catastrophizing, distress, and pain behaviors appear to be closely associated development of disability. Catastrophization, anxiety, and negative emotions facilitate excitatory descending pain pathways and inhibit inhibitory descending pain pathways [105]. Psychological factors, especially distress, depressive mood, and somatization, increase one's vulnerability for transition from acute to chronic low back pain [106]. The development of serious disability due to low back pain in a cohort of subjects with both structural and psychosocial risk factors was strongly predicted by baseline psychosocial variables, whereas structural variables on both MRI and discography testing at baseline had only weak association with back pain episodes and no association with disability or future medical care [107].

Central nervous system development and brain function later in life are adversely affected by exposure to adverse childhood experiences in a dose dependent manner, leaving those exposed with dysfunctional coping mechanisms and susceptibility to central sensitization [108]. Personality disorders are often the ultimate expression of these experiences; they complicate physician-patient interactions and employee-supervisor interactions. Borderline personality disorder is the most common personality disorder and is equally prevalent in men and women. People with borderline personality disorder use medical care more often than the general population. The causes are not yet clear, but genetic factors and adverse life events seem to interact to lead to the disorder. Borderline personality disorder is characterized by a pervasive pattern of instability of interpersonal relationships, poor self-image, and marked impulsivity beginning by early adulthood and present in a variety of contexts [109]. These workers are ill-equipped to handle stress and conflict. Proper modulation of the autonomic nervous system is vital to a functional stress 
response. The key component of this system appears to be the vagus nerve [110]. The Polyvagal Theory proposes that the evolution of the mammalian autonomic nervous system provides the neurophysiological substrates for adaptive behavioral strategies [111]. Evidence suggests that dysfunction of the parasympathetic component of the autonomic nervous system is a possible neurophysiological determinant of borderline personality disorder [108]. The exaggerated vagal withdrawal promotes mobilization behaviors which compromise social engagement. This leaves one prone to impulsiveness, hyperreactivity and emotional dysregulation, and each are a barrier to recovery from injuries.

\section{Interventions}

The assistance of a Workers' Compensation liaison can help a patient navigate the complexities of the workers' compensation system and facilitate approval for treatment modalities, imaging studies, and specialty referrals. This mitigates external stress and allows the worker to concentrate on recovering.

Periodic screening for depression, anxiety, and substance use disorders may be offered as a component of the company's wellness program. A systematic metaanalysis [112] examined the effectiveness of workplace mental health interventions aimed at facilitating the recovery of employees diagnosed with depression or anxiety and found moderate evidence for two primary prevention interventions including enhancing employee control and promoting physical activity. Stronger evidence was found for cognitive behavioral therapy-based stress management. Little evidence was found for other secondary prevention interventions, such as counselling. Tertiary interventions with a specific focus on work, including exposure therapy and cognitive behavioral therapy (CBT)-based and problem-focused return-to-work programs, showed strong evidence for improving symptoms and a moderate evidence base for improving occupational outcomes [112].

Adding cognitive-behavioral interventions appears to lead to fewer health care visits, less work absenteeism, and less long-term disability for patients with work-related pain $[14,27,28]$. Cognitive behavioral training (CBTr) is rooted in cognitive behavioral theory, but it is not therapy. It is a didactic curriculum broken up into a series of progressive, purposefully ordered sessions, each one with a specific focus [14]. CBTr unfolds sequentially, guiding the participant through the process of retraining the brain and dissolving the emotionally dependent thinking, and it is meant to mitigate kinesiophobia and catastrophization, and foster problem-solving [14]. Success with CBTr is largely dependent on the active, cooperative participation of the worker.
The forebrain can influence the origin of the descending pathway located in brainstem nuclei via a mechanism termed cognitive emotional sensitization. Patients who are misinformed about pain will often consider their pain as threatening and demonstrate cognitive distortions such as catastrophic thinking and rumination. These patients tend to not comply with active treatments. A 2011 Institute of Medicine report on pain [113] recommended providing patients with pain education focusing on self-management and biological and psychological factors early in the patient's course to prevent pain from becoming chronic. Pain physiology education helps to amend pain perceptions including catastrophizing and fear avoidance. Providing written pain education materials alone has not been shown to alter perceptions [114]. However, improvement was noted when the same written material is provided with two face-toface educational sessions. Pain physiology education is indicated when the clinical picture is characterized by central sensitization and when maladaptive illness perceptions are present [114].

The use of a clinical decision tool, such as the Subgroups for Targeted Treatment-Musculoskeletal (STarT MSK) questionnaire to identify misconceptions regarding pain, fear avoidance, or catastrophizing may be advantageous [20]. The STarT MSK questionnaire assigns the patient to one of three stratified risk categories based on STarT MSK results. This stratified management approach improved care use and disability measures at 4- and 12-month follow-ups; measures of physical and emotional functioning, pain intensity, quality of life, days off work, and treatment satisfaction have been shown to be higher than those of the nonstratified current best practice control group $[19,20]$. Low risk patients identified by the STarT-MSK tool should receive conservative care as determined by current clinical guidelines and OMT protocols for the given diagnoses. Moderate risk patients should receive guideline-directed care along with referral to physical therapy. High risk patients should receive care per guideline recommendations and are referred for psychologically augmented physical therapy if available. Limiting OMT techniques to gentle modalities such as Jones strain-counterstrain and myofascial release is recommended for this group. A referral for CBT can be considered to address any cognitive distortions if psychologically augmented physical therapy is not available.

The endocannabinoid system plays a functional role in nociception and each of the brain structures important for processing anxiety, fear, and stress [115]. Stress induces altered expression of two endocannabinoid molecules, anandamide (AEA), and 2-arachidonoyl glycerol (2-AG). Stress exposure reduces AEA levels and increases 2-AG levels. The decline of AEA levels contributes to the 
manifestations of the stress response and anxiety behavior, including activation of the hypothalamic-pituitary-adrenal axis [115]. Evidence suggests that OMT may ameliorate these effects by increasing levels of AEA [116, 117].

Furthermore, suboccipital decompression appears to decrease stress by increasing vagal tone. Rib raising decreases sympathetic tone by releasing the costotransverse articulations found underneath the sympathetic chain ganglion arising from T1 to L2 [118]. A single cranial OMT session appeared to restore sympathovagal balance after an acute mental stressor by dampening parasympathetic withdrawal and sympathetic tone [119].

\section{Discussion}

Silverstein and Clark [120] performed a systematic review of RCTs, 17 quasi-experimental studies, and 36 case studies of interventions aimed at reducing work-related musculoskeletal disorders. With the exception of exercise, individual interventions were not particularly effective. They concluded that combinations of measures have the greatest effect in reducing work-related musculoskeletal disorders relative to single interventions [120].

The current review has taken a novel approach by examining the development and prevention of workrelated musculoskeletal injuries within the context of the five models of osteopathic care. The presented osteopathic model of the development and prevention of work-related musculoskeletal disorders coincides with Silverstein and Clark's review [116] in that a combination of preventive interventions will be more effective than any single preventive intervention. This approach has the added benefit of furnishing a holistic arrangement to the presented findings. Table 2 summarizes the findings of the current review, presenting recommended preventive interventions and the corresponding highest level of evidence.

The primary limitation of this review is that it did not employ a mixed-treatment comparison. The heterogenous nature of the study designs failed to meet the assumptions of homogeneity, transitivity, and consistency. Sources of heterogeneity included study designs, the variety of industries represented, the outcome measures, and the population demographics. Therefore, performing such a comparative analysis was not possible. While a systematic review was performed for the clinical controlled trials used in the preventive intervention component of the review, no systematic review was performed for the nonclinical studies used for the pathophysiology component. This increased the risk of bias in the selection of articles for inclusion in the review.
The literature reviewed here suggests that OMT techniques can positively affect many of the identified processes associated with the development of occupational musculoskeletal disorders. However, there is a paucity of research investigating the effectiveness of OMT as a preventive intervention. Future research evaluating the effects of OMT as a preventive intervention within the context of the five models of osteopathic care is warranted.

\section{Conclusions}

With an understanding of how injuries develop, preventive resources can be directed to where they will likely have the greatest impact. The presented osteopathic approach suggests several areas where targeted primary, secondary, and tertiary preventive interventions may be effective. According to the biomechanical-structural model, interventions that match demands to capacity, correct dysfunctional movement patterns, and limit tissue vulnerability to stress may mitigate the risk of occupational musculoskeletal injury and disability. The neurological model suggests that restoring alpha-gamma balance, tonic-phasic synergistic function, and autonomic balance are central to an injury prevention program. Measures that maximize physiologic reserve are key to the metabolic-energy model component of a prevention program, while the respiratory-circulatory component of a comprehensive prevention program depends upon measures that optimize respiration and circulation. Finally, the importance of the behavioral-biopsychosocial model is imperative as unaddressed cognitive distortions likely hinder all other preventive measures.

Research funding: None declared.

Author contributions: The author has accepted responsibility for the entire content of this manuscript and approved its submission.

Competing interests: Author states no conflict of interest.

\section{References}

1. Leigh JP. Economic burden of occupational injury and illness in the United States. Milbank Q 2011;89:728-72.

2. Bhattacharya A. Costs of occupational musculoskeletal disorders (MSDs) in the United States. Int J Ind Ergon 2014;44:448-54.

3. Leigh JP, Marcin J. Workers' compensation benefits and shifting costs for occupational injury and illness. J Occup Environ Med 2012;54:445-50.

4. Dembe AE, Erickson JB, Delbos R. Predictors of work-related injuries and illnesses: national survey findings. J Occup Environ Hyg 2004;1:542-50. 
5. Visser B, van Dieën J. Pathophysiology of upper extremity muscle disorders. J Electromyogr Kinesiol 2006;16:1-16.

6. Solomonow M. Ligaments: a source of work-related musculoskeletal disorders. J Electromyogr Kinesiol 2004;14:49-60.

7. Frank C, Page P, Lardner R. Assessment and treatment of muscle imbalance: the Janda approach. Champaign, IL: Human Kinetics; 2009.

8. Maganaris C, Narici M, Almekinders L, Maffulli N. Biomechanics and pathophysiology of overuse tendon injuries. Sports Med 2004;34:1005-17.

9. Seffinger MA, Amirianfar E, Kuchera ML, Jerome JA. The five models of osteopathic care. In: Seffinger M, editor. Foundations of osteopathic medicine: philosophy, science, clinical applications, and research, 4th ed. Philadelphia, PA: Wolters Kluwer; 2018:300-24 pp.

10. NICE. The guidelines manual. National Institute for Health and Care Excellence Website; 2009. http://wwwnice.org.uk/ guidelinesmanual [Accessed 15 Jan 2020].

11. Bruce-Low S, Smith D, Burnet S, Fisher J, Bissell G, Webster L. One lumbar extension training session per week is sufficient for strength gains and reductions in pain in patients with chronic low back pain ergonomics. Ergonomics 2012;55:500-7.

12. Chaléat-Valayer E, Denis A, Abelin-Genevois K, Zelmar A, SianiTrebern $F$, Touzet $S$, et al. Long-term effectiveness of an educational and physical intervention for preventing low-back pain recurrence: a randomized controlled trial. Scand J Work Environ Health 2016;42:510-9.

13. Comper ML, Dennerlein JT, Evangelista GD, Rodrigues DS, Padula RS. Effectiveness of job rotation for preventing work-related musculoskeletal diseases: a cluster randomised controlled trial. Occup Environ Med 2017;74:543-4.

14. Dahl JC, Nilsson A. Evaluation of a randomized preventive behavioural medicine work site intervention for public health workers at risk for developing chronic pain. Eur J Pain 2001;5: 421-32.

15. Esmaeilzadeh S, Ozcan E, Capan N. Effects of ergonomic intervention on work-related upper extremity musculoskeletal disorders among computer workers: a randomized controlled trial. Int Arch Occup Environ Health 2014;87:73-83.

16. Greene BL, DeJoy DM, Olejnik S. Effects of an active ergonomics training program on risk exposure, worker beliefs, and symptoms in computer users. Work 2005;24:41-52.

17. Grooten WJ, Mulder M, Wiktorin C. The effect of ergonomic intervention on neck/shoulder and low back pain. Work 2007;28: 313-23.

18. Harbin GL, Shenoy C, Garcia A, Olson JC. Shoulder injury reduction with post-offer testing. Work 2011;39:113-23.

19. Hill J, Whitehurst D, Lewis M, Bryan S, Dunn K, Foster N, et al. Comparison of stratified primary care management for low back pain with current best practice (STarT Back): a randomised controlled trial. Lancet 2011;378:1560-71.

20. Hill J, Afolabi E, Lewis M, Dunn K, Roddy E, van der Windt D, et al. Does a modified STarT Back Tool predict outcome with a broader group of musculoskeletal patients than back pain? A secondary analysis of cohort data. BMJ Open 2016;6:e012445.

21. Horneij E, Hemborg B, Jensen I, Ekdahl C. No significant differences between intervention programmes on neck, shoulder and low back pain: a prospective randomized study among homecare personnel. J Rehabil Med 2001;33:170-6.
22. Jakobsen M, Sundstrup E, Brandt M, Andersen L. Effect of physical exercise on musculoskeletal pain in multiple body regions among healthcare workers: secondary analysis of a cluster randomized controlled trial. Musculoskel Sci Pract 2018; 34:89-96.

23. Járomi M, Kukla A, Szilágyi B, Simon-Ugron Á, Bobály VK, Makai A, et al. Back school programme for nurses has reduced low back pain levels: a randomised controlled trial. J Clin Nurs 2018;27: e895-902.

24. Jensen L, Gonge H, Jørs E, Ryom P, Foldspang A, Christensen M, et al. Prevention of low back pain in female eldercare workers: randomized controlled work site trial. Spine 2006;31:1761-9.

25. Jørgensen MB, Faber A, Hansen JV, Holtermann A, Søgaard K. Effects on musculoskeletal pain, work ability and sickness absence in a 1-year randomised controlled trial among cleaners. BMC Publ Health 2011;11:840.

26. Levanon Y, Gefen A, Lerman Y, Givon U, Ratzon NZ. Reducing musculoskeletal disorders among computer operators: comparison between ergonomics interventions at the workplace. Ergonomics 2012;55:1571-85.

27. Linton S, Boersma K, Jansson M, Svärd L, Botvalde M. The effects of cognitive-behavioral and physical therapy preventive interventions on pain-related sick leave. Clin J Pain 2005;21: 109-19.

28. Menzel NN, Robinson ME. Back pain in direct patient care providers: early intervention with cognitive behavioral therapy. Pain Manag Nurs 2006;7:53-63.

29. Moreira-Silva I, Santos R, Abreu S, Mota J. The effect of a physical activity program on decreasing physical disability indicated by musculoskeletal pain and related symptoms among workers: a pilot study. Int J Occup Saf Ergon JOSE. 2014;20:55-64.

30. Rantonen J, Karppinen J, Vehtari A, Luoto S, Viikari-Juntura E, Hupli $M$, et al. Effectiveness of three interventions for secondary prevention of low back pain in the occupational health setting: $a$ randomised controlled trial with a natural course control. BMC Publ Health 2018;18:598.

31. Rantonen J, Luoto S, Vehtari A, Hupli M, Karppinen J, Malmivaara A, et al. The effectiveness of two active interventions compared to self-care advice in employees with non-acute low back symptoms: a randomised, controlled trial with a 4-year follow-up in the occupational health setting. Occup Environ Med 2010;69:12-20.

32. Rasotto C, Bergamin M, Sieverdes JC, Gobbo S, Alberton CL, Neunhaeuserer $D$, et al. A tailored workplace exercise program for women at risk for neck and upper limb musculoskeletal disorders: a randomized controlled trial. J Occup Environ Med 2015;57:178-83.

33. Rasotto C, Bergamin M, Simonetti A, Maso S, Bartolucci GB, Ermolao A, et al. Tailored exercise program reduces symptoms of upper limb work-related musculoskeletal disorders in a group of metalworkers: a randomized controlled trial. Man Ther 2015;20: 56-62.

34. Rempel DM, Krause N, Goldberg R, Benner D, Hudes M, Goldner GU. A randomised controlled trial evaluating the effects of two workstation interventions on upper body pain and incident musculoskeletal disorders among computer operators. Occup Environ Med 2006;63:300-6.

35. Robertson M, O’Neill M. Reducing musculoskeletal discomfort: effects of an office ergonomics workplace and training intervention. Int J Occup Saf Ergon 2003;9:491-502. 
36. Shiri R, Martimo KP, Miranda H, Ketola R, Kaila-Kangas L, Liira H, et al. The effect of workplace intervention on pain and sickness absence caused by upper-extremity musculoskeletal disorders. Scand J Work Environ Health 2011;37:120-8.

37. Sjögren T, Nissinen KJ, Järvenpää SK, Ojanen MT, Vanharanta $H$, Mälkiä EA. Effects of a workplace physical exercise intervention on the intensity of low back symptoms in office workers: a cluster randomized controlled cross-over design. J Back Musculoskelet Rehabil 2006;19:13-24.

38. Sundstrup E, Jakobsen M, Brandt M, Jay K, Persson R, Aagaard P, et al. Workplace strength training prevents deterioration of work ability among workers with chronic pain and work disability: a randomized controlled trial. Scand J Work Environ Health 2014; 40:244-51.

39. Tunwattanapong P, Kongkasuwan R, Kuptniratsaikul V. The effectiveness of a neck and shoulder stretching exercise program among office workers with neck pain: a randomized controlled trial. Clin Rehabil 2016;30:64-72.

40. Yassi A, Cooper JE, Tate RB, Gerlach S, Muir M, Trottier J, et al. A randomized controlled trial to prevent patient lift and transfer injuries of health care workers. Spine 2001;26:1739-46.

41. Educational Council on Osteopathic Principles. Glossary of osteopathic terminology. Chicago, IL: American Association of Colleges of Osteopathic Medicine; 2011.

42. Conwit R, Stashuk D, Suzuki H, Lynch N, Schrager M, Metter EJ. Fatigue effects on motor unit activity during submaximal contractions. Arch Phys Med Rehabil 2000;81:1211-6.

43. Sharma P, Maffulli N. Biology of tendon injury: healing, modeling and remodeling. J Musculoskelet Neuronal Interact 2006;6: 181-90.

44. Riley G, Curry V, DeGroot J, van El B, Verzijl N, Hazleman B, et al. Matrix metalloproteinase activities and their relationship with collagen remodeling in tendon pathology. Matrix Biol 2002;21: 185-95.

45. Riley G. The pathogenesis of tendinopathy. A molecular perspective. Rheumatology 2003;43:131-42.

46. Serra C, Rodriguez M, Delclos G, Plana M, López L, Benavides F. Criteria and methods used for the assessment of fitness for work: a systematic review. Occup Environ Med 2007;64:304-12.

47. Schaafsma F, Mahmud N, Reneman M, Fassier J, Jungbauer F. Preemployment examinations for preventing injury, disease and sick leave in workers. Cochrane Database Syst Rev 2016;1: CD008881.

48. Linton SJ, van Tulder MW. Preventive interventions for back and neck pain problems: what is the evidence? Spine 2001;26: 778-87.

49. Steffens D, Maher CG, Pereira LS, Stevens ML, Oliveira VC, Chapple M, et al. Prevention of low back pain: a systematic review and meta-analysis. JAMA Intern Med 2016;176:199-208.

50. Padula RS, Comper MLC, Sparer EH, Dennerlein JT. Job rotation designed to prevent musculoskeletal disorders and control risk in manufacturing industries: a systematic review. Appl Ergon 2017;58:386-97.

51. Van Eerd D, Munhall C, Irvin E, Rempel D, Brewer S, Van Der Beek AJ, et al. Effectiveness of workplace interventions in the prevention of upper extremity musculoskeletal disorders and symptoms: an update of the evidence. Occup Environ Med 2016;73:62-70.

52. Bigos SJ, Holland J, Holland C, Webster JS, Battie M, Malmgren JA. High-quality controlled trials on preventing episodes of back problems: systematic literature review in working-age adults. Spine J 2009;9:147-68.

53. van Duijvenbode I, Jellema P, van Poppel M, van Tulder MW. Lumbar supports for prevention and treatment of low back pain. Cochrane Database Syst Rev 2008;2:CD001823.

54. Jellema P, van Tulder MW, van Poppel M, Nachemson AL, Bouter LM. Lumbar supports for prevention and treatment of low back pain: a systematic review within the framework of the Cochrane Back Review Group. Spine 2001;26:377-86.

55. Patterson M, Wurster R. Somatic dysfunction, spinal facilitation, and viscerosomatic reflex. In: Seffinger, M, editor. Foundations of osteopathic medicine: philosophy, science, clinical applications, and research, 4th ed. Philadelphia, PA: Wolters Kluwer; 2018: 300-24 pp.

56. Latremoliere A, Woolf C. Central sensitization: a generator of pain hypersensitivity by central neural plasticity. J Pain 2009;10: 895-926.

57. Meeus M, Nijs J. Central sensitization: a biopsychosocial explanation for chronic widespread pain in patients with fibromyalgia and chronic fatigue syndrome. Clin Rheumatol 2007;26:465-73.

58. Honma S, Seki Y. Muscle spindles in phasic and tonic muscle. Tohoku J Exp Med 1964;83:391-7.

59. Patterson M. A model mechanism for spinal segmental facilitation. J Am Osteopath Assoc 1976;76:62-72.

60. Winter J, Allen T, Proske U. Muscle spindle signals combine with the sense of effort to indicate limb position. J Physiol 2005;568: 1035-46.

61. Proske U, Allen T. Damage to skeletal muscle from eccentric exercise. Exerc Sport Sci Rev 2005;33:98-104.

62. Paschalis V, Nikolaidis M, Giakas G, Jamurtas A, Pappas A, Koutedakis $Y$. The effect of eccentric exercise on position sense and joint reaction angle of the lower limbs. Muscle Nerve 2007; 35:496-503.

63. Gribble P, Hertel J. Effect of lower-extremity muscle fatigue on postural control. Arch Phys Med Rehabil 2004;85:589-92.

64. Johanson E, Brumagne S, Janssens L, Pijnenburg M, Claeys K, Pääsuke $M$. The effect of acute back muscle fatigue on postural control strategy in people with and without recurrent low back pain. Eur Spine J 2011;20:2152-9.

65. da Costa BR, Vieira ER. Stretching to reduce work-related musculoskeletal disorders: a systematic review. J Rehabil Med 2008;40:321-8.

66. Hruby R. Pathophysiologic models: aids to the selection of manipulative techniques. Am Acad Osteopathy J 1991;1:8-10.

67. Ruffini N, D’Alessandro G, Mariani N, Pollastrelli A, Cardinali L, Cerritelli $\mathrm{F}$. Variations of high frequency parameter of heart rate variability following osteopathic manipulative treatment in healthy subjects compared to control group and sham therapy: randomized controlled trial. Front Neurosci 2015;9:272.

68. Jäkel $A$, von Hauenschild P. Therapeutic effects of cranial osteopathic manipulative medicine: a systematic review. J Am Osteopath Assoc 2011;111:685-93.

69. Henderson A, Fisher J, Li T, Bridges K. Effects of rib raising on the autonomic nervous system: a pilot study using noninvasive biomarkers. J Am Osteopath Assoc 2010;110:324-30.

70. Howell J, Cabell K, Chila A, Eland D. Stretch reflex and Hoffmann reflex responses to osteopathic manipulative treatment in subjects with Achilles tendinitis. J Am Osteopath Assoc 2006; 106:537-45. 
71. Zlott D, Byrne M. Mechanisms by which pharmacologic agents may contribute to fatigue. Phys Med Rehabil 2010;2:451-5.

72. Alibazi RJ, Moghadam AN, Zarrabi V, Bakhshi E, Nakhaei N. The effect of muscle fatigue on normal biomechanics of shoulder girdle: a systematic review of the literature. Arch Rehabil 2015;16: 242-51.

73. McQuade K, Wei SH, Smidt G. Effects of local muscle fatigue on three-dimensional scapulohumeral rhythm. Clin BioMech 1995; 10:144-8.

74. Geiser C, O'Connor K, Earl J. Effects of isolated hip abductor fatigue on frontal plane knee mechanics. Med Sci Sports Exerc 2010;42:535-45.

75. Thomas A, McLean S, Palmieri-Smith R. Quadriceps and hamstrings fatigue alters hip and knee mechanics. J Appl Biomech 2010;6:159-70.

76. Westerblad H, Allen D, Lännergren J. Muscle fatigue: lactic acid or inorganic phosphate the major cause? Physiology 2002;17: 17-21.

77. Amann M, Romer L, Pegelow D, Jacques AH, Dempsey J. Effects of arterial oxygen content on peripheral locomotor muscle fatigue. I Appl Physiol 2006;101:119-27.

78. Jones L, Kusunose R, Goering E. Jones strain-counterstrain. Boise, ID: Jones Strain-Counterstrain, Inc; 1995.

79. d'Avella A, Fernandez L, Portone A, Lacquaniti F. Modulation of phasic and tonic muscle synergies with reaching direction and speed. J Neurophysiol 2008;100:1433-54.

80. Gissel H. $\mathrm{Ca}^{2+}$ accumulation and cell damage in skeletal muscle during low frequency stimulation. Eur J Appl Physiol 2000;83: 175-80.

81. Ashley N, Weil Z, Nelson R. Inflammation: mechanisms, costs, and natural variation. Annu Rev Ecol Evol Systemat 2012;43: 385-406.

82. Mense S. Pathophysiology of low back pain and the transition to the chronic state-experimental data and new concepts. Schmerz 2001;15:413-7.

83. Tallima H, El Ridi R. Arachidonic acid: physiological roles and potential health benefits. A review. J Adv Res 2018;11:33-41.

84. Scallan J, Huxley V, Korthuis R. Pathophysiology of edema formation. In: Scallan J, Huxley V, Korthuis R, editors. Capillary fluid exchange: regulation, functions, and pathology. Morgan \& Claypool Life Sciences; 2010.

85. Crow TW. The effects of manipulation on ligaments and fascia from a fluids model perspective. Am Acad Osteopathy J 2006;16: 13-9.

86. Isernhagen $\mathrm{S}$. Introduction to functional capacity evaluation. In: Genovese E, Galper JS, editors. Guide to the evaluation of functional ability: how to request, interpret, and apply functional capacity evaluations. Chicago, IL: American Medical Association; 2009:1-18 pp.

87. Anderson C, Briggs J. A study of the effectiveness of ergonomically-based functional screening tests and their relationship to reducing worker compensation injuries. Work 2008;31:27-37.

88. Talmage J, Melhorn J. A physician's guide to return to work. Chicago, IL: American Medical Association; 2005.

89. DeSalvo K, Olson R, Casavale K. Dietary guidelines for Americans. J Am Med Assoc 2016;315:457-8.

90. Thomas-Valdés S, Tostes M, Anunciação P, da Silva B, Sant'Ana H. Association between vitamin deficiency and metabolic disorders related to obesity. Crit Rev Food Sci Nutr 2017;7:3332-43.
91. John S, Hoegerl C. Nutritional deficiencies after gastric bypass surgery. J Am Osteopath Assoc 2009;109:601-4.

92. Fields H, Ruddy B, Wallace M, Shah A, Millstine D, Marks L. How to monitor and advise vegans to ensure adequate nutrient intake. J Am Osteopath Assoc 2016;116:96-9.

93. Syamlal G, King BA, Mazurek JM. Tobacco use among working adults-United States, 2014-2016. MMWR Morb Mortal Wkly Rep 2017;66:1130-5.

94. Lee $\mathrm{C}$, Chang W. The effects of cigarette smoking on aerobic and anaerobic capacity and heart rate variability among female university students. Int J Wom Health 2013;5:667-79.

95. Al-Bashaireh A, Haddad L, Weaver M, Kelly D, Chengguo X, Yoo S. The effect of tobacco smoking on musculoskeletal health: a systematic review. J Environ Publ Health 2018;2018:418490.

96. Abate M, Vanni D, Pantalone A, Salini V. Cigarette smoking and musculoskeletal disorders. Muscles Ligaments Tendons J 2013; 3:63-9.

97. Papadakis S, McDonald P, Mullen KA, Reid R, Skulsky K, Pipe A. Strategies to increase the delivery of smoking cessation treatments in primary care settings: a systematic review and meta-analysis. Prev Med 2010;51:199-213.

98. Meltzer KR, Standley PR. Modeled repetitive motion strain and indirect osteopathic manipulative techniques in regulation of human fibroblast proliferation and interleukin secretion. J Am Osteopath Assoc 2007;107:527-36.

99. Wong CK. Strain counterstrain: current concepts and clinical evidence. Man Ther 2012;17:2-8.

100. Pope RE. The common compensatory pattern: its origin and relationship to the postural model. Am Acad Osteopathy J 2003; 14:19-40.

101. Benjamin M. The fascia of the limbs and back - a review. J Anat 2009;214:1-18.

102. Ajimsha M, Al-Mudahka N, Al-Madzhar J. Effectiveness of myofascial release: systematic review of randomized controlled trials. J Bodyw Mov Ther 2015;19:102-12.

103. Shaw W, Pransky G, Patterson W, Winters T. Early disability risk factors for low back pain assessed at outpatient occupational health clinics. Spine 2005;30:572-80.

104. Nicholas M, Linton S, Watson P, Main C. Early identification and management of psychological risk factors ("yellow flags") in patients with low back pain: a reappraisal. Phys Ther 2011;91: 737-53.

105. Sullivan MJ, Stanish W, Waite H, Sullivan M, Tripp DA. Catastrophizing, pain, and disability in patients with soft-tissue injuries. Pain 1998;77:253-60.

106. Pincus T, Burton A, Vogel S, Field A. A systematic review of psychological factors as predictors of chronicity/disability in prospective cohorts of low back pain. Spine 2002;27:109-20.

107. Carragee E, Alamin T, Miller J, Carragee J. Discographic, MRI and psychosocial determinants of low back pain disability and remission: a prospective study in subjects with benign persistent back pain. Spine J 2005;5:24-35.

108. Austin M, Riniolo T, Porges S. Borderline personality disorder and emotion regulation: insights from the Polyvagal Theory. Brain Cognit 2007;65:69-76.

109. American Psychiatric Association. Diagnostic and statistical manual of mental disorders, 5th ed. Arlington, VA: American Psychiatric Publishing; 2013.

110. Porges S. The Polyvagal Theory: phylogenetic contributions to social behavior. Physiol Behav 2003;9:503-23. 
111. Porges S. The Polyvagal Theory: new insights into adaptive reactions of the autonomic nervous system. Cleve Clin J Med 2009;76:s86.

112. Joyce S, Modini M, Christensen H, Mykletun A, Bryant R, Mitchell $P$, et al. Workplace interventions for common mental disorders: a systematic meta-review. Psychol Med 2016;46: 683-97.

113. Simon LS. Relieving pain in America: a blueprint for transforming prevention, care, education, and research. J Pain Palliat Care Pharmacother 2012;26:197-8.

114. Nijs J, Van Wilgen C, Van Oosterwijck J, van Ittersum M, Meeus M. How to explain central sensitization to patients with 'unexplained' chronic musculoskeletal pain: practice guidelines. Man Ther 2011;16:413-8.

115. Morena M, Patel S, Bains J, Hill M. Neurobiological interactions between stress and the endocannabinoid system. Neuropsychopharmacology 2016;41:80-102.
116. McPartland J, Giuffrida A, King J, Skinner E, Scotter J, Musty R. Cannabimimetic effects of osteopathic manipulative treatment. J Am Osteopath Assoc 2005;105:283-91.

117. McPartland J. The endocannabinoid system: an osteopathic perspective. J Am Osteopath Assoc 2008;108:586-600.

118. Emmet D, Nuno V, Pierce-Talsma S. OMT to address the physiologic effects of stress. J Am Osteopath Assoc 2018; 118:e11.

119. Fornari M, Carnevali L, Sgoifo A. Single osteopathic manipulative therapy session dampens acute autonomic and neuroendocrine responses to mental stress in healthy male participants. J Am Osteopath Assoc 2017;117:559-67.

120. Silverstein $B$, Clark R. Interventions to reduce work-related musculoskeletal disorders. J Electromyogr Kinesiol 2004;14:135-52.

121. Schander A, Downey HF, Hodge LM. Lymphatic pump manipulation mobilizes inflammatory mediators into lymphatic circulation. Exp Biol Med 2012;237:58-63. 